\title{
Acute Psychosis: An Atypical First Presentation of Advanced HIV Infection
}

\author{
Nicholas Michael D'Ardenne*, Eric Gluck and Panayiota Govas
}

Croydon University Hospital, London, UK

\begin{abstract}
Primary presentation of HIVIAIDS can be greatly varied, with continued emphasis on primary prevention and early detection of infection; there should be a decreasing number of atypical initial presentations. It has been shown that chronic disease results in an increased risk of people developing depression, and that psychiatric features may be the only symptoms of non-malignant brain lesions. These two points combined shows that there is a possibility that HIV, a chronic medical condition, could have a psychiatric presentation. This is atypical though, and therefore is an interesting teaching point, especially in the importance of ruling out organic conditions in the presentation of psychiatric diagnosis.
\end{abstract}

Keywords: HIV; AIDS; Psychosis; Depression; Toxoplasmosis; CD4

\section{Introduction}

Primary presentation of HIV/AIDS can be greatly varied, with continued emphasis on primary prevention and early detection of infection; there should be a decreasing number of atypical initial presentations. It has been shown that chronic disease results in an increased risk of people developing depression [1] and that psychiatric feature may be the only symptoms of non-malignant brain lesions [2]. These two points combined shows that there is a possibility that HIV, a chronic medical condition, could have a psychiatric presentation. This is atypical though, and therefore is an interesting teaching point, especially in the importance of ruling out organic conditions in the presentation of psychiatric diagnosis.

\section{Case Presentation}

A 32 year old, unmarried, Nigerian female, who had emigrated to the US many years prior. This patient travels back and forth regularly between the two countries. She presented to a community hospital Emergency Department in Chicago, Illinois with worsening depression, confusion and new onset delusions and visual hallucinations. Past medical history is only significant for recurrent infections over the past 8-10 years with multiple known infections of malaria and typhoid fever, as reported by the patients' mother. The patient was not oriented to place or time on admission, and had explained frank delusions to her mother. As per local protocol, because of a first presentation of psychiatric illness the patient underwent computed tomography (CT). The CT demonstrated a lesion in the Basal Ganglia, and the patient underwent a MRI. The MRI showed a heterogeneously enhancing lesion in the left Basal Ganglia with an area of enhancement (ring) measuring $4.3 \mathrm{~cm}$. There was also an $8 \mathrm{~mm}$ right midline shift.

Positive findings on physical examination included hyper pigmented macular lesions that are apparently chronic in nature, as per the patient's mother. The patient was confused to her unfamiliar surrounds in the hospital but was orientated to person and time. She exhibited some expressive aphasia, but there was no gross neurological deficit, with movements and strength was symmetrical bilaterally. Laboratory findings on admission where significant for mild anemia and leukopenia. The patients Rapid Plasma Reagin was negative and her HIV screen was reactive. The patient received seizure prophylaxis and steroids; further investigation of the HIV infection was undertaken. Her HIV-1 viral load was determined to be $1,875,000$ copies per $\mathrm{mL}$ of plasma and she had a CD4 count of 2 .

The patients' clinical picture improved and the following day she was communicative, alert and oriented. Treatment options where discussed and it was decided that a stereotactic brain biopsy of the lesion should be undertaken. Before the biopsy the patient deteriorated developing a right facial droop and hemiparesis.

The patient underwent a left frontal craniotomy and stereotactic brain biopsy. The procedure was completed without intraoperative complication and two biopsy samples where sent for histopathology. The patient was transferred to ICU for monitoring. The patient was alert however anxious and disoriented. On examination the cranial nerve and neurological examination was normal. Intracranial pressure (ICP) was increasing and the clinical picture of the patient was deteriorating. She vomited and was sent for CT which showed left cerebral hemisphere, basal ganglia and brainstem infarction and cerebral edema. There was mass effect and herniation of the brain through the craniectomy. Upon returning to the ICU nursing staff noted dilated pupils and decreasing saturations. The patient was intubated and returned to the operating room for an emergency craniectomy to relieve the increasing pressure. Once the patient returned from the craniectomy the ICP continued to rise, measured at $11 \mathrm{mmHg}$ upon return to the ICU, increasing to $39 \mathrm{~mm} \mathrm{Hg}, 10 \mathrm{~h}$ post-surgery. At this point there was no retained neurological function or reflexes and the patient was maintained by the ventilator. Two days later the patient failed an apnea test and was pronounced dead.

\section{Discussion}

With increasing knowledge of HIV and improvements to treatment regimes, especially Highly Active Antiretroviral Therapy (HAART), the diagnosis of HIV infection shouldn't be as mortal as it once was. Study data from different demographics show that there is still a generalized delay in diagnosis with studies in South Africa, China and the United States reporting CD4 counts at the time of diagnosis 364 cells $/ \mathrm{mm}^{3}, 294$ cells $/ \mathrm{mm}^{3}$ and 314 cells $/ \mathrm{mm}^{3}$ respectfully [3-5]. The study of Buchacz

*Corresponding author: Nicholas Michael D'Ardenne, Senior House Officer, Croydon University Hospital, Emergency, 530 London Rd, Croydon, London, London CR7 7YE, United Kingdom; Tel: +447478508240; E-mail: n.d'ardenne@nhs.net

Received July 20, 2017; Accepted August 01, 2017; Published August 08, 2017

Citation: D'Ardenne NM, Gluck E, Govas P (2017) Acute Psychosis: An Atypical First Presentation of Advanced HIV Infection. J AIDS Clin Res 8: 717. doi: 10.4172/2155 6113.1000717

Copyright: (c) 2017 D'Ardenne NM, et al. This is an open-access article distributed under the terms of the Creative Commons Attribution License, which permits unrestricted use, distribution, and reproduction in any medium, provided the original author and source are credited. 
et al. showed 'no statistically significant improvement in the median CD4 count at diagnosis during 2000-2009 [5], indicating an alarming example of the work that is still needed to be done on HIV education and early detection. This being said, there are some studies which show an increase in the CD4 cell level at the time of the diagnosis, although only minor advances are occurring the upward trend shows that maybe progress is occurring [6,7]. The development in early detection, with placement of new protocols in healthcare systems, may improve patient prognosis due to a decrease in the number of patients presenting with advanced infection. In 2005, 38\% of patients diagnosed with HIV had advanced to a diagnosis of AIDS within 1 year of their diagnosis [8], showing the need for a continual improvement in early detection.

With early detection of HIV infection there will ideally be decreasing numbers of patients like the one reported in this case where their initial presentation is both, atypical and of fulminant disease. There is evidence to support the notion that the more advanced the disease is the greater likelihood of psychotic symptoms to be present $[9,10]$. The likely explanation is, the increased prevalence of CNS opportunistic infection causing organic psychosis $[10,11]$. This view is supported with a cross-sectional study, which showed, an increase in prevalence of symptoms shown by the patient in this case; delirium, frank psychosis and depression, being increased in patients with CNS opportunistic infection rather than just regular HIV infection [9].

There is a noted correlation between toxoplasmosis infection and psychosis in all patients not just those infected with HIV $[12,13]$ and there is also a documented relationship between decreasing CD4 count in HIV infected patients and worsening depression, especially in females [14]. For these reasons there should be no surprise that the diagnosis of HIV/ Toxoplasmosis remains a possibility in a patient presenting to hospital. There is however a diagnostic dilemma when a patient presents to the ER, with psychiatric symptoms, like this patient. The patient should always be investigated with no prejudice or preconceived ideas as to an underlying diagnosis. Local protocols must be adhered to allowing all possible differential diagnoses to be considered. There is also a greater correlation of risky behavior in patients with psychiatric conditions that could lead to infection with HIV making these patients at greater risk of becoming HIV positive. This premorbid psychotic disorder increases the chance of their being an acute psychotic event leading to the initial presentation in the hospital [15]. This creates another dilemma to determine if the psychosis is separate to the concurrent HIV infection or caused by it.

\section{Conclusion}

HIV infection can appear clinically in many forms; generally physicians are looking for physical signs that are more commonly associated with the disease. Although this thought process is not flawed as this is, statistically speaking, most likely to yield results it must not be forgotten there are atypical presentations of HIV infection. Mental illness specifically psychotic depression is not commonly recorded as an initial presentation of advanced HIV infection but, as this case has shown, should be considered in the differential of organic causes of mental health conditions.

\section{References}

1. Moussavi S (2007) Depression, chronic diseases and decrements in health Results from the world health surveys. Lancet 370: 851-858.

2. Gupta RK, Kumar R (2015) Benign brain tumours and psychiatric morbidity: A 5 years retrospective data analysis. Aust N Z J Psychiatry 38: 316-319.

3. Govender S, Otwombe K, Essien T, Panchia R, de Bruyn G, et al. (2015) CD4 counts and viral loads of newly diagnosed HIV-infected individuals: Implications for treatment as prevention. PLoS ONE 9: e90754.

4. Tang H, Mao Y, Shi CX, Han J, Wang L, et al. (2014) Baseline CD4 cell counts of newly diagnosed HIV cases in China: 2006-2012. PLoS ONE 9: e96098.

5. Buchacz K, Armon C, Palella FJ, Baker RK, Tedaldi E, et al. (2012) CD4 cell counts at HIV diagnosis among HIV outpatient study participants, 2000-2009. AIDS Research and Treatment 2012: 1-7.

6. http://apps.who.int/iris/bitstream/10665/85321/1/9789241505727_eng.pdf

7. Althoff KN, Gange SJ, Klein MB, Brooks JT, Hogg RS, et al. (2010) Late presentation for human immunodeficiency virus care in the United States and Canada. Clin Infect Dis 50: 1512-1520.

8. http://www.cdc.gov/hiv/topics/surveillance/resources/reports/2006report/ default.htm.

9. Sewell DD (1996) Schizophrenia and HIV. Schizophrenia Bulletin 22: 465-473

10. Navia BA, Jordan BD, Price RW (1986) The AIDS dementia complex: I clinical features. Ann Neurol 19: 517-524.

11. Koutsilieri E, Scheller C, Sopper S, ter Meulen V, Riederer P, et al. (2002) Psychiatric complications in human immunodeficiency virus infection. J Neurovirol 8: 129-133.

12. Amminger GP (2016) Serum antibodies against toxoplasma gondii are associated with more positive symptoms in individuals at ultra-high risk for psychosis. Schizophrenia Research 86: S78.

13. Zhu S (2009) Psychosis may be associated with toxoplasmosis. Med Hypotheses 73: 799-801.

14. Ickovics JR, Hamburger ME, Vlahov D, Schoenbaum EE, Schuman P, et al (2001) Mortality, CD4 cell count decline and depressive symptoms among HIVseropositive women. JAMA 285: 1466-1474.

15. Nebhinani N, Mattoo SK, Wanchu A (2011) Psychiatric morbidity in HIV-positive subjects: A study from India. J Psychosom Res 70: 449-454. 